\title{
Evaluation of multiple forcing data sets for precipitation and shortwave radiation over major land areas of China
}

\author{
Fan Yang ${ }^{1}$, Hui Lu ${ }^{1,2}$, Kun Yang ${ }^{1,2,3,4}$, Jie He ${ }^{4}$, Wei Wang ${ }^{1,5}$, Jonathon S. Wright ${ }^{1,2}$, Chengwei Li ${ }^{1}$, Menglei Han ${ }^{1}$, and \\ Yishan $\mathbf{L i}^{1}$ \\ ${ }^{1}$ Ministry of Education Key Laboratory for Earth System Modeling, Department of Earth System Science, \\ Tsinghua University, Beijing, 100084, China \\ ${ }^{2}$ The Joint Center for Global Change Studies, Beijing, 100875, China \\ ${ }^{3}$ CAS Center for Excellence in Tibetan Plateau Earth System, Beijing, 100101, China \\ ${ }^{4}$ Key Laboratory of Tibetan Environment Changes and Land Surface Processes, Institute of Tibetan Plateau \\ Research, Chinese Academy of Sciences, Beijing, 100101, China \\ ${ }^{5}$ Changjiang Institute of Survey, Planning, Design and Research, Wuhan, 430010, China
}

Correspondence to: Hui Lu (luhui@tsinghua.edu.cn)

Received: 31 May 2017 - Discussion started: 8 June 2017

Revised: 16 October 2017 - Accepted: 17 October 2017 - Published: 23 November 2017

\begin{abstract}
Precipitation and shortwave radiation play important roles in climatic, hydrological and biogeochemical cycles. Several global and regional forcing data sets currently provide historical estimates of these two variables over China, including the Global Land Data Assimilation System (GLDAS), the China Meteorological Administration (CMA) Land Data Assimilation System (CLDAS) and the China Meteorological Forcing Dataset (CMFD). The CN05.1 precipitation data set, a gridded analysis based on CMA gauge observations, also provides high-resolution historical precipitation data for China. In this study, we present an intercomparison of precipitation and shortwave radiation data from CN05.1, CMFD, CLDAS and GLDAS during 20082014. We also validate all four data sets against independent ground station observations. All four forcing data sets capture the spatial distribution of precipitation over major land areas of China, although CLDAS indicates smaller annual-mean precipitation amounts than CN05.1, CMFD or GLDAS. Time series of precipitation anomalies are largely consistent among the data sets, except for a sudden decrease in CMFD after August 2014. All forcing data indicate greater temporal variations relative to the mean in dry regions than in wet regions. Validation against independent precipitation observations provided by the Ministry of Water Resources (MWR) in the middle and lower reaches of the Yangtze River indicates that CLDAS provides the most realistic estimates
\end{abstract}

of spatiotemporal variability in precipitation in this region. CMFD also performs well with respect to annual mean precipitation, while GLDAS fails to accurately capture much of the spatiotemporal variability and CN05.1 contains significant high biases relative to the MWR observations. Estimates of shortwave radiation from CMFD are largely consistent with station observations, while CLDAS and GLDAS greatly overestimate shortwave radiation. All three forcing data sets capture the key features of the spatial distribution, but estimates from CLDAS and GLDAS are systematically higher than those from CMFD over most of mainland China. Based on our evaluation metrics, CLDAS slightly outperforms GLDAS. CLDAS is also closer than GLDAS to CMFD with respect to temporal variations in shortwave radiation anomalies, with substantial differences among the time series. Differences in temporal variations are especially pronounced south of $34^{\circ} \mathrm{N}$. Our findings provide valuable guidance for a variety of stakeholders, including land-surface modelers and data providers.

\section{Introduction}

Precipitation and shortwave radiation are the fundamental sources of water and energy for land-surface biological, physical and chemical processes (Zhao and Zhu, 2015; 
Zhang et al., 2010). These fluxes affect moisture and heat exchange between the atmosphere and the land surface (Pan et al., 2014; Tian et al., 2007; Fekete et al., 2004; Gottschalck et al., 2005), and are key meteorological forcing inputs for studies using land process models, including crop simulation, hydrologic modeling, dryland expansion estimation and analysis of dust events (Bart and Lettenmaier 2004; Tang et al., 2008; Huang et al., 2016; Kang et al., 2016). Accurate estimates of precipitation and shortwave radiation are therefore essential for studies of climate change and land-surface processes.

Although conventional station-based measurements can obtain the values of a measured variable with high accuracy and precision, these measurements can only represent information at local scales (Maurer et al., 2002; Bogh et al., 2004), and are unable to adequately depict spatial variations given the limited number and locations of stations (Duan et al., 2012). In the late 1980s, data assimilation techniques were proposed as a means of reconstructing historical forcing data at high resolution (Xie et al., 2011; Zhao et al., 2010). This innovation brought unprecedented opportunities for researchers. The resulting forcing data sets, which typically include precipitation, shortwave radiation, temperature, specific humidity, wind speed, surface pressure and other meteorological data, are derived by assimilating numerical weather forecast information, ground observation data and remote sensing data into an analysis product (Xie et al., 2011; Zhao et al., 2010; Pan et al., 2010). Many forcing data sets are now available, including the National Centers for Environmental Prediction and the National Center for Atmospheric Research reanalysis (NCEP/NCAR; Kalnay et al., 1996), the Global Land Data Assimilation System (GLDAS; Rodell et al., 2004), the European Centre for Medium-Range Weather Forecasts (ECMWF) Interim Reanalysis (ERA-Interim; Dee et al., 2011) and the Japanese 55-year Reanalysis (JRA-55; Kobayashi et al., 2015), among many others. In recent years, Chinese researchers have made great progress in developing forcing data sets. Through these efforts, two forcing data sets covering China have been produced, namely the China Meteorological Forcing Dataset (CMFD), released by the Institute of Tibetan Plateau Research, Chinese Academy of Sciences (He and Yang, 2011), and the China Meteorological Administration (CMA) Land Data Assimilation System (CLDAS; Shi et al., 2014). Separate efforts have produced new gridded analyses of station-based measurements, including the CN05.1 interpolation of CMA rain gauge data released by the National Climate Center (Wu and Gao, 2013). These forcing data sets are widely used because they have high spatial resolution, cover a large area over a long period and are convenient to obtain and process. For example, CMFD forcing data have been used to simulate permafrost and seasonally frozen ground conditions on the Tibetan Plateau (Guo and Wang, 2013), to analyze the impacts of precipitation on springtime vegetation phenology (Shen et al., 2015), to model the landsurface water and energy cycles in a mesoscale watershed
(Xue et al., 2013) and to assess climatic and human impacts on surface water resources in the middle reaches of the Yellow River (Hu et al., 2015). The CMFD and GLDAS forcing data sets have also been used to improve land-surface temperature modeling for arid regions in China (Chen et al., 2011), while GLDAS has been applied to analyze long-term variations in terrestrial water storage in the Yangtze River basin (Huang et al., 2013) and the recently released CLDAS has been adopted in a recent drought monitoring study (Han, 2015). The CN05.1 data set also has been used in many fields, such as simulating climate change over China (Gao et al., 2013) and studying shifts in the western Pacific subtropical high (Huang et al., 2015).

However, forcing data have considerable uncertainties, regardless of whether these data are generated by interpolating ground observations or derived from reanalysis products (Qian et al., 2006). Biases associated with a forcing data set can propagate into model results (Wang et al., 2016b), which may in turn be unrealistic if the forcing data are unreliable (Cosgrove et al., 2003). For example, errors in precipitation and shortwave radiation can have profound impacts on simulations of soil moisture, runoff and heat fluxes (Luo et al., 2003). It is therefore necessary to evaluate the accuracy of forcing data sets so that the relevant biases are fully recognized when they are applied in studies of land-surface processes (Pan et al., 2014).

Several previous studies have evaluated the forcing data sets examined in this work. Y. Wang et al. (2016) evaluated the performance of CMFD daily precipitation estimates over the Qinghai-Tibetan Plateau from 2009 to 2012 and found systematic overestimates through much of the year (more than 255 days). Wang et al. (2014, 2016a) assessed the reliability of GLDAS monthly precipitation data in China from 1979 to 2012 by visual comparison with direct observations, and found that both GLDAS-1 and GLDAS-2 precipitation match the direct observations well. Wang et al. (2011) validated GLDAS-1 daily and monthly precipitation data for a mesoscale basin in northeast China during March 2003 to March 2006, and concluded that both daily and monthly precipitation estimates from GLDAS were of high quality. Wang and Zeng (2012) evaluated six reanalysis products (MERRA, NCEP-NCAR, CFSR, ERA-40, ERA-Interim and GLDAS1) against in situ measurements from 63 weather stations on the Tibetan Plateau, and found that GLDAS provided the best overall performance with respect to both daily and monthly precipitation.

Although the quality of GLDAS data has been validated and confirmed by previous studies, these data are not biasfree. In particular, the credibility of GLDAS over continental China in recent years has yet to be assessed. The CN05.1, CMFD and CLDAS data sets have been developed and maintained by Chinese scientists and are supposed to be accurate and reliable because they are more strictly constrained by surface observations. However, no comprehensive evaluation of these forcing data sets has yet been conducted over 
major land areas of China (including mainland China and the two biggest islands off the coast, Hainan and Taiwan). In this study, we present an intercomparison of precipitation and shortwave radiation products from CN05.1, CMFD, CLDAS and GLDAS, along with an evaluation against available in situ observations. The results of this intercomparison will assist researchers in selecting and understanding meteorological forcing data, and will also help to guide further innovations and improvements in these data sets.

\section{Data}

\subsection{Forcing data sets}

\subsubsection{CN05.1}

CN05.1 provides precipitation along with daily mean, minimum and maximum temperatures (Wu and Gao, 2013). In this paper, we use $0.25^{\circ} \times 0.25^{\circ}$ gridded monthly precipitation data over mainland China. These data have been interpolated from more than 2000 gauge stations over China. An "anomaly approach" (New et al., 2000) was applied during the interpolation step. As meteorological stations are mainly located in eastern China where the terrain is flatter and the economy is more developed, CN05.1 may have large uncertainties in western China.

\subsubsection{CMFD}

The CMFD forcing data set was developed by the Institute of Tibetan Plateau Research, Chinese Academy of Sciences (He and Yang, 2011). This product covers the region $70-140^{\circ} \mathrm{E}$ and $15-55^{\circ} \mathrm{N}$, and includes precipitation, downward shortwave radiation, downward longwave radiation, $2 \mathrm{~m}$ air temperature, specific humidity, wind speed and surface pressure. The Tropical Rainfall Measuring Mission (TRMM) 3B42 precipitation product is used as the background field for the precipitation analysis; however, this product provides relative few data north of $40^{\circ} \mathrm{N}$ and no data north of $50^{\circ} \mathrm{N}$. GLDAS precipitation estimates are used as the background state in these regions. Gauge observation data from 740 stations in the CMA network are used to correct systematic departures in the background data. Global Energy and Water cycle Experiment-Surface Radiation Budget (GEWEX$\mathrm{SRB}$ ) radiation data are used as the background state for the CMFD shortwave radiation analysis. As with precipitation, GLDAS is used to replace GEWEX-SRB when the latter is unavailable. CMA station measurements of shortwave radiation (see Sect. 2.2.2) are used to adjust this background state. Additional basic information for these data is listed in Table 1 .

\subsubsection{CLDAS}

We evaluate version 2.0 of the CLDAS data set. This data set was developed by CMA (Shi et al., 2014) and provides hourly spatial coverage within $60-160^{\circ} \mathrm{E}$ and $0-65^{\circ} \mathrm{N}$ on a $0.0625 \times 0.0625^{\circ}$ grid. The CLDAS data set includes a variety of land-surface forcing data, including precipitation, shortwave radiation, temperature, specific humidity, wind speed and surface pressure, as well as soil status variables. It is a relatively new product, with temporal coverage from 2008 to 2017. Precipitation is combined and interpolated from two products, the Climate Prediction Center Morphing Technique (CMORPH) analysis and an hourly merged precipitation analysis (V1.0) produced by CMA. The latter merges observations made at automatic weather stations in China together with CMORPH analyses using a probability density function (PDF) and optimal interpolation (OI) algorithm (Shen et al., 2014). Shortwave radiation is retrieved from the FY-2C/E series of geostationary meteorological satellites. The Discrete Ordinates Radiative Transfer Program for a Multi-Layered Plane-Parallel Medium (DISORT) method is used for radiation transfer calculations in conducting the retrievals (Shi et al., 2011).

\subsubsection{GLDAS}

The $0.25^{\circ} \times 0.25^{\circ}$ monthly GLDAS-1 forcing data (shortened to GLDAS in this paper) is provided by the US National Aeronautics and Space Administration (NASA). Precipitation estimates in this version are based on the $\mathrm{Na}$ tional Oceanic and Atmospheric Administration (NOAA) Climate Prediction Center Merged Analysis of Precipitation (CMAP), which combines satellite data (IR and microwave) with gauge measurements. CMAP estimates are downscaled to higher spatial and temporal resolutions using simulated precipitation fields from the Global Data Assimilation System (GDAS). Cloud and snow products from the Air Force Weather Agency (AFWA) Agricultural Meteorology modeling system (AGRMET) are used to calculate downward shortwave and longwave radiation fluxes via an AFWAsupplied procedure (Rui and Beaudoing, 2017; Rodell et al., 2004).

\subsection{Validation data set}

\subsubsection{MWR precipitation data}

We use precipitation observations from a rain gauge network maintained by the Hydrology Bureau in the Ministry of Water Resources (MWR) of China (Xu et al., 2017) as reference data for validating the forcing data sets. In this study, we use precipitation measurements collected from rain gauges located in Hubei, Hunan and Jiangxi provinces during 2014. These MWR-provided precipitation data are independent of the forcing data sets, which use data from surface stations operated by CMA. Data from 5490 stations are suitable for 
Table 1. Basic information of the forcing data sets and the MWR precipitation data used to validate them.

\begin{tabular}{llrrlrr}
\hline Name & Type & $\begin{array}{r}\text { Analyzed } \\
\text { period }\end{array}$ & $\begin{array}{r}\text { Available } \\
\text { period }\end{array}$ & Variables & $\begin{array}{r}\text { Spatial } \\
\text { resolution }\end{array}$ & $\begin{array}{r}\text { Number of } \\
\text { sites }\end{array}$ \\
\hline CN05.1 & forcing data set & $2008-2014$ & $1961-2014$ & precipitation & $0.25^{\circ}$ & $0.1^{\circ}$ \\
CMFD & forcing data set & $2008-2014$ & $1979-2016$ & precipitation; shortwave radiation & $0.0625^{\circ}$ & $0.25^{\circ}$ \\
CLDAS & forcing data set & $2008-2014$ & $2008-2016$ & precipitation; shortwave radiation & precipitation; shortwave radiation & 5490 \\
GLDAS & forcing data set & $2008-2014$ & $2000-2016$ & precipitation & 2014 & \\
MWR & observation data & 2014 & 2014 & & &
\end{tabular}

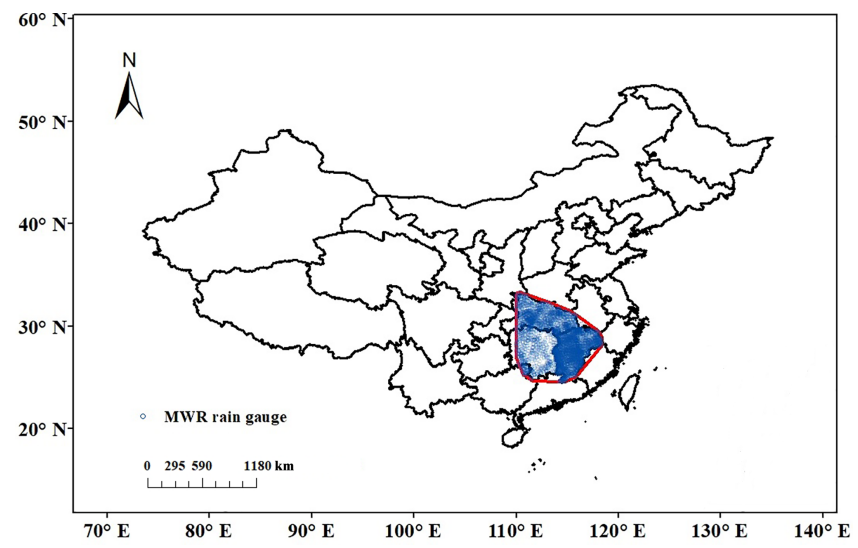

Figure 1. Locations of rain gauges operated by the Ministry of Water Resources of China, used as an independent source of precipitation data for validating the forcing data sets.

inclusion in this study after quality control procedures. The locations of these stations are shown in Fig. 1.

\subsubsection{Shortwave radiation station data}

We use two station-based shortwave radiation data sets to validate the forcing data. The first is an estimated data set based on the station data provided by CMA. This data set has some mutual dependence with CMFD, as it estimates radiation fluxes using a hybrid model that is not fully independent of the background data used for CMFD. The second stationbased data set is independent of all four forcing data sets. Figure 2 shows the distribution of stations in these two networks, with basic information for these data listed in Table 2.

1. Station-based shortwave radiation fluxes from CMA.

Daily estimates of surface solar radiation through 2010 are provided by the Data Assimilation and Modeling Center for Tibetan Multi-spheres (http://dam.itpcas.ac.cn/data/daily_solar_radiation_ dataset_over_China_readme.htm). This data set is produced using data from two sources. The first source is a hybrid model (Yang et al., 2001, 2006) based on air temperature, air pressure, relative humidity and sunshine duration at $716 \mathrm{CMA}$ stations. The other is an ANN-based (artificial neural network) model at 96 radiation stations. Owing to the high accuracy of the ANN-based model, these estimates are used to dynamically correct the hybrid model estimates at monthly timescales. The ANN-based model has been trained using recent observations to estimate historical variations in shortwave radiation at the 96 radiation stations (Tang et al., 2013). For this validation, we select 625 stations with full data coverage during 2008-2010.

2. Independent station-based shortwave radiation fluxes.

(a) CERN shortwave radiation stations.

The Chinese Ecosystem Research Network (CERN) was established in 1988 by the Chinese Academy of Sciences (Su et al., 2005). We use observations of shortwave radiation provided by 35 CERN field stations covering a variety of ecosystems during 2008-2014, including farmlands, forests, grasslands, lakes and coastal regions. As shown in Fig. 2, these stations are distributed relatively evenly across mainland China and cover a range of climate regimes. The CERN stations are independent of the CMA stations used in CMFD and CLDAS, and therefore provide an ideal reference for validating the estimates of shortwave radiation provided in these three forcing data sets despite their relatively sparse spatial density.

(b) HiWATER shortwave radiation stations.

Observations of shortwave radiation have been collected at eight stations in the Heihe River for the Heihe Watershed Allied Telemetry Experimental Research (HiWATER) campaign (Li et al., 2013). These data have been widely used for land-surface process studies (Liu et al., 2016; Cheng et al., 2014). Among the eight stations, $2-3$ sites are distributed in each of the upper, middle and lower reaches of the Heihe River basin.

(c) TPE shortwave radiation stations.

Daily records of shortwave radiation from the meteorological data sets of the Ngari Desert Observation and Research Station and the Muztagh Ata Station for Westerly Environment Observation and 
Table 2. Basic information for shortwave radiation observation data used to validate the forcing data sets.

\begin{tabular}{|c|c|c|c|c|c|c|}
\hline Name & Type & $\begin{array}{l}\text { Analyzed } \\
\text { period }\end{array}$ & $\begin{array}{l}\text { Available } \\
\text { period }\end{array}$ & Variables & $\begin{array}{l}\text { Spatial } \\
\text { resolution }\end{array}$ & $\begin{array}{r}\text { Number of } \\
\text { sites }\end{array}$ \\
\hline CMA & observation data & 2008-2010 & different at each site & shortwave radiation & & 625 \\
\hline CERN & observation data & 2008-2014 & different at each site & shortwave radiation & & 35 \\
\hline HiWATER & observation data & different at each site & different at each site & shortwave radiation & & 8 \\
\hline TPE Database & observation data & different at each site & different at each site & shortwave radiation & & 2 \\
\hline
\end{tabular}

Table 3. Statistical metrics summarizing the spatial average and variability of annual mean precipitation during 2008-2014.

\begin{tabular}{lrrrr}
\hline Metrics & CN05.1 & CMFD & CLDAS & GLDAS \\
\hline Mean $\left(\mathrm{mm} \mathrm{yr}^{-1}\right)$ & 612.09 & 637.65 & 508.58 & 609.44 \\
SD $\left(\mathrm{mm} \mathrm{yr}^{-1}\right)$ & 497.61 & 511.09 & 429.50 & 506.55 \\
CV & 0.81 & 0.80 & 0.84 & 0.83 \\
\hline
\end{tabular}

Research are obtained from the Third Pole Environment (TPE) Database (http://www.tpedatabase.cn). These stations along the western border of China, as shown in Fig. 2, and are used to evaluate the performance of the three forcing data sets over the western Tibetan Plateau, where very few CMA ground stations are located.

\section{Methodology}

We validate estimates of precipitation and shortwave radiation on a variety of spatial and temporal scales. Three metrics are computed from each data set for mainland China: the area-weighted average (mean), the standard deviation (SD) and the coefficient of variation $(\mathrm{CV})$. The latter two metrics reflect the amplitude of internal variance within the data set. Monthly anomalies are derived by subtracting the 7-year monthly climatology. We then use temporal coefficient of variation (TCV) to compare temporal fluctuations across the forcing data sets. A larger value of TCV indicates greater temporal variability. For further comparisons, CMFD and CLDAS are resampled to match the $0.25^{\circ} \times 0.25^{\circ}$ grid intrinsic to the CN05.1 and GLDAS data sets using bilinear interpolation. Validation against gauge- and station-based observations is conducted by using a pixel-point method (Chen et al., 2013) to pair station data with the appropriate gridded forcing data. Evaluation metrics used in this pixel-point comparison include the root-mean-square error (RMSE) and bias. Bias reflects the degree to which the forcing data set over- or underestimates the reference data. Taylor diagrams (Taylor, 2001) are used to further describe the correspondence between forcing data and reference data. These diagrams show the ratio of standardized deviations, the correlation coefficient and the unbiased RMSE between the forc- ing data and the reference observations. These statistics can quantify how well the forcing data resembles the observation. These metrics are formulated as follows:

$\begin{aligned} \mathrm{SD} & =\sqrt{\frac{1}{N} \sum_{i=1}^{N}\left(x_{i}-\bar{x}\right)^{2}}, \\ \mathrm{CV} & =\frac{\mathrm{SD}}{\bar{x}},\end{aligned}$

Correlation coefficient $=\frac{\sum_{i=1}^{N}\left(x_{i}-\bar{x}\right)\left(y_{i}-\bar{y}\right)}{\sqrt{\sum_{i=1}^{N}\left(x_{i}-\bar{x}\right)^{2} \sum_{i=1}^{N}\left(y_{i}-\bar{y}\right)^{2}}}$,

$\mathrm{RMSE}=\sqrt{\frac{\sum_{i=1}^{N}\left(x_{i}-y_{i}\right)^{2}}{N}}$,

Bias $=\sum_{i=1}^{N} x_{i}-\sum_{i=1}^{N} y_{i}$,

Relative bias $=\frac{\sum_{i=1}^{N} x_{i}}{\sum_{i=1}^{N} y_{i}}-1$,

$\mathrm{TCV}=\frac{\sqrt{\frac{1}{m} \sum_{j=1}^{m}\left(t_{j}-\bar{t}\right)^{2}}}{\bar{t}}$,

where $x_{i}$ is an element of the evaluated data set and $\bar{x}$ is the average value for the evaluated data set; $y_{i}$ is an element of the reference data set and $\bar{y}$ is the average for the reference data set; $N$ is the number of data points included in the comparison; $m$ is the number of months during 2008 to 2014 with valid data in both data sets; $t_{j}$ is a gridded monthly value of precipitation or shortwave radiation; $\bar{t}$ is the average of $t_{j}$.

\section{Evaluation of precipitation data}

\subsection{Spatial distribution of precipitation}

Figure 3 shows the spatial distributions of precipitation based on the four forcing data sets. All four data sets capture the 


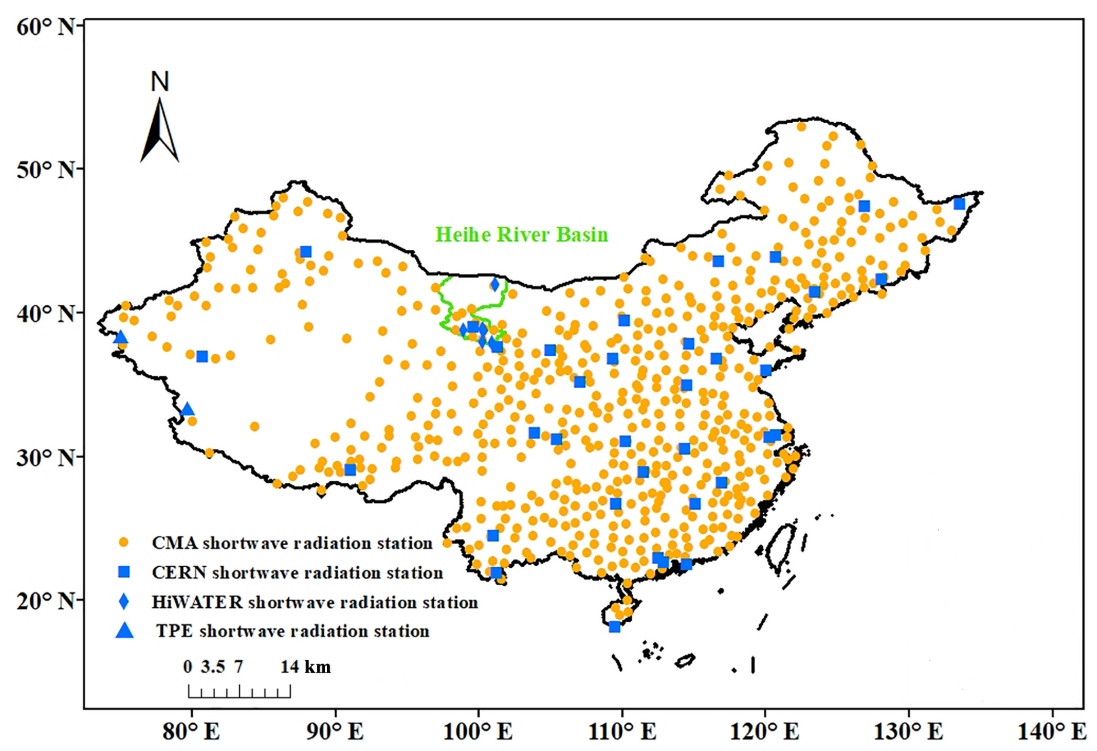

Figure 2. Locations of shortwave radiation stations in mainland China used to validate the forcing data sets.

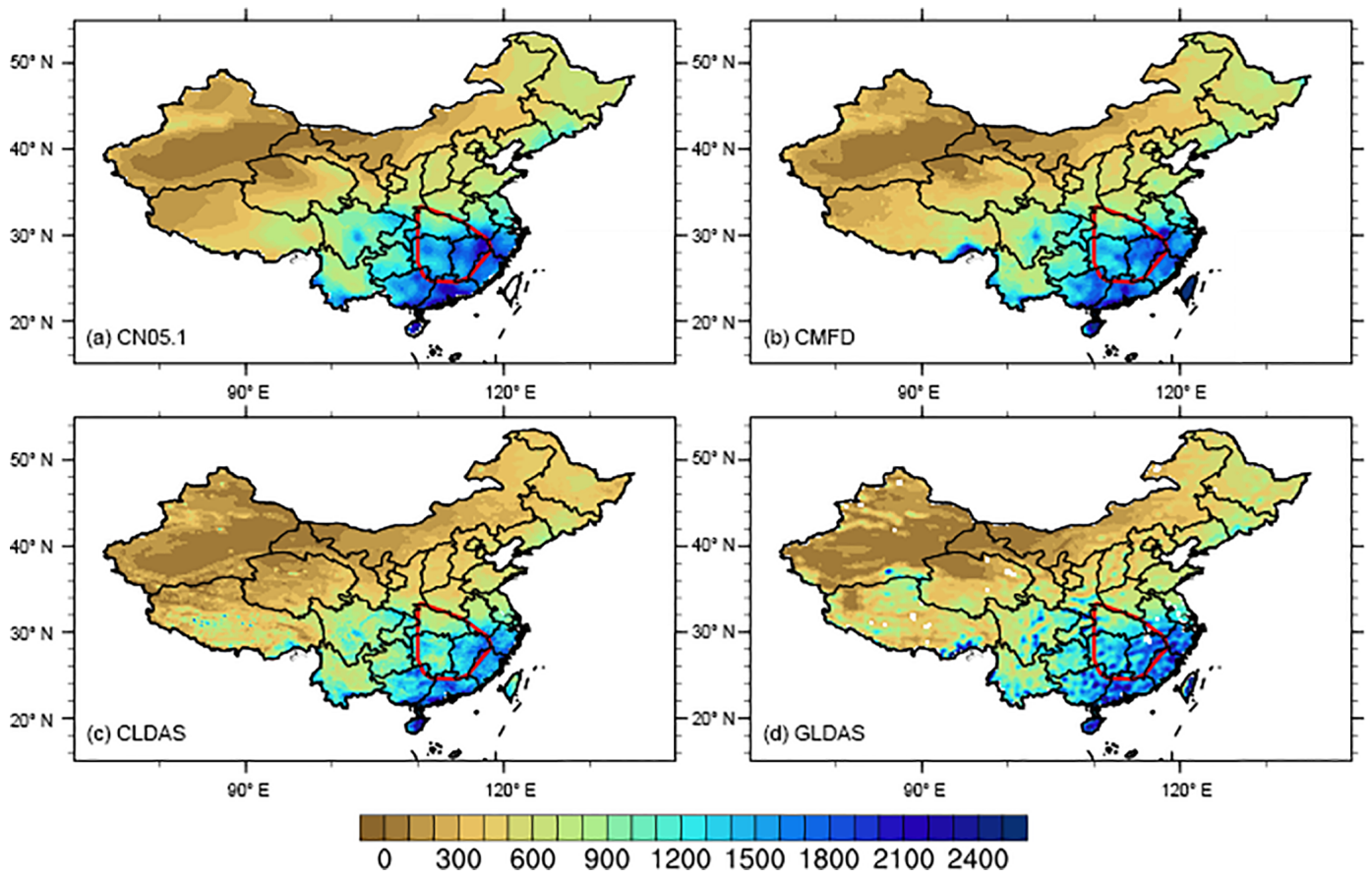

Figure 3. Spatial distributions of annual-mean precipitation over 2008-2014 (unit: $\mathrm{mm} \mathrm{yr}^{-1}$ ) from (a) CN05.1, (b) CMFD, (c) CLDAS and (d) GLDAS.

increase in annual mean precipitation from northwest China to southeast China. The distributions of precipitation based on CMFD and CN05.1 are generally similar, although these two data sets still have some mutual discrepancies in western China (e.g., over the Tibetan Plateau). The area for which annual mean precipitation exceeds $1500 \mathrm{~mm}$ is smaller in CLDAS and GLDAS than in CN05.1 and CMFD, and precipitation over northern China is considerably smaller in
CLDAS than in the other three data sets. As shown in Table 3, mean precipitation over China is significantly lower in CLDAS, while CMFD has the largest mean value. The spatial SD and CV are more similar among the four data sets. 
Table 4. Statistical metrics summarizing the performance of monthly precipitation estimates based on forcing data sets in 2014 relative to MWR rain gauge observations (unit: $\mathrm{mm} \mathrm{month}^{-1}$ for monthly data and $\mathrm{mm} \mathrm{yr}^{-1}$ for annual data).

\begin{tabular}{|c|c|c|c|c|c|c|c|c|}
\hline \multirow[b]{2}{*}{ Time } & \multicolumn{4}{|c|}{ Bias } & \multicolumn{4}{|c|}{ RMSE } \\
\hline & CN05.1 & CMFD & CLDAS & GLDAS & CN05.1 & CMFD & CLDAS & GLDAS \\
\hline Jan & 23.62 & 2.37 & -1.85 & -0.48 & 29.53 & 19.70 & 8.90 & 8.26 \\
\hline Feb & 48.04 & 31.53 & 4.74 & 20.43 & 59.13 & 59.87 & 26.19 & 37.15 \\
\hline Mar & 61.37 & 14.81 & -9.26 & 12.50 & 77.02 & 37.54 & 36.43 & 59.47 \\
\hline Apr & 62.83 & 17.93 & -8.47 & 12.39 & 79.06 & 47.63 & 35.86 & 67.15 \\
\hline May & 66.23 & 24.72 & 13.32 & 39.51 & 93.05 & 66.51 & 52.63 & 105.35 \\
\hline Jun & 40.11 & 23.59 & 0.49 & 19.48 & 74.53 & 67.77 & 50.06 & 87.73 \\
\hline Jul & 18.68 & 7.38 & -0.24 & 1.04 & 67.86 & 78.26 & 59.45 & 92.06 \\
\hline Aug & 22.37 & -53.29 & 3.57 & 11.01 & 62.51 & 78.93 & 47.46 & 74.30 \\
\hline Sept & 4.58 & -21.18 & -8.57 & 1.74 & 36.81 & 45.66 & 32.35 & 44.09 \\
\hline Oct & 26.07 & -17.59 & 5.56 & 8.72 & 37.11 & 38.95 & 27.76 & 32.35 \\
\hline Nov & 26.73 & -21.04 & -2.91 & 14.36 & 37.71 & 34.76 & 25.95 & 40.79 \\
\hline Dec & 8.99 & -5.43 & -4.33 & -1.65 & 14.90 & 16.97 & 9.40 & 10.84 \\
\hline Annual & 421.38 & 3.80 & -7.93 & 139.06 & 403.16 & 273.68 & 234.39 & 427.71 \\
\hline
\end{tabular}

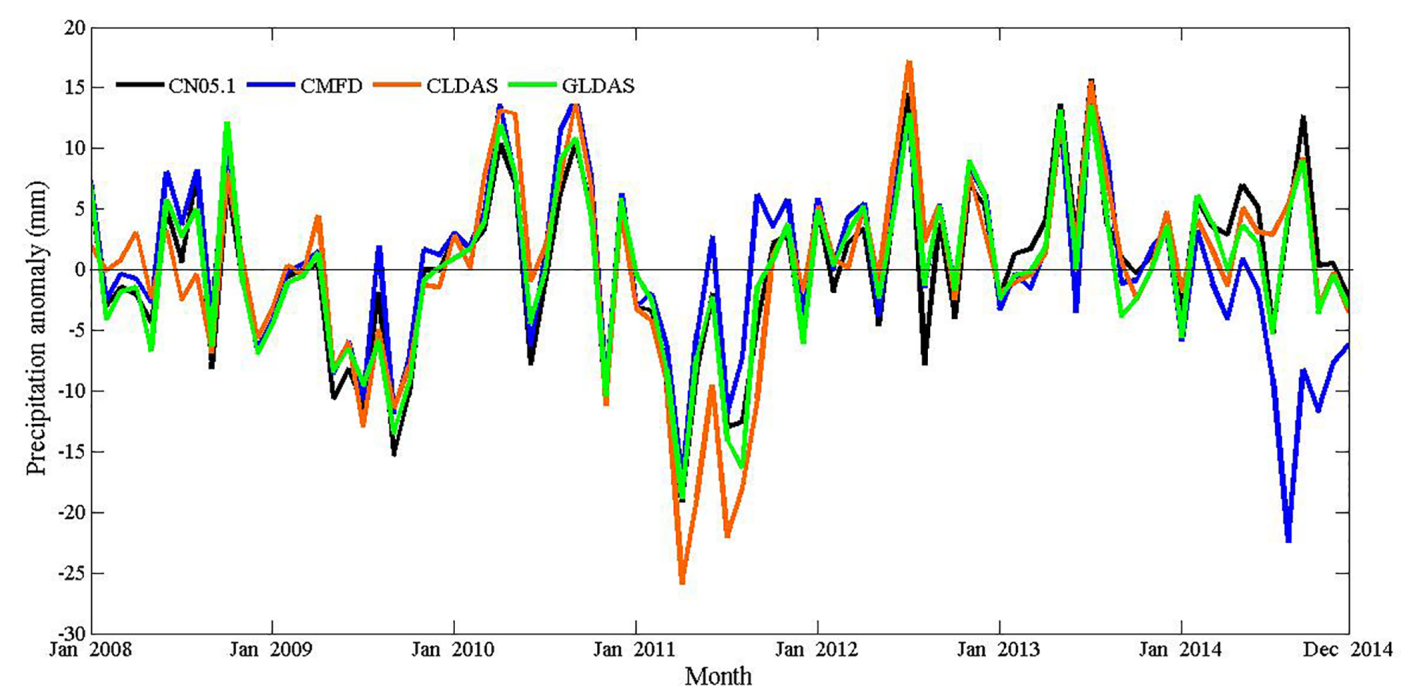

Figure 4. Time series of monthly mean precipitation anomalies from CN05.1 (black), CMFD (blue), CLDAS (orange) and GLDAS (green).

\subsection{Temporal variations in precipitation}

Figure 4 shows time series of monthly mean precipitation anomalies averaged over mainland China based on the four forcing data sets. The four data sets match each other well through most of the evaluation period, indicating that these forcing data sets generally reproduce interannual and decadal variability in mean precipitation averaged over mainland China. Notably, mean precipitation anomalies based on CMFD are lower than those based on the other data sets after August 2014. Figure 5 shows the spatial distribution of the TCV, which represents the temporal standard deviation normalized by the mean value in each grid cell during the 7-year analysis period. The spatial distribution of TCV in southeast China is similar among the four data sets, with small values through most of this region. The four data sets also show similar distributions of normalized variance in northern China, where interannual variability is much stronger. Values of TCV are generally similar between CMFD and CN05.1, while CLDAS and GLDAS indicate greater variance in most areas of northern China, especially in dry regions (Xinjiang, Gansu and Inner Mongolia) where TCV values may exceed 1.5. The area in which TCV exceeds 1.0 is larger in CLDAS than in the other three forcing data sets. Likewise, the mean value of TCV averaged over major land areas of China is largest in CLDAS.

\subsection{Comparison with MWR station data}

Comparison of the spatial distributions of precipitation based on the four forcing data sets reveals evident differences among these data sets in the middle and lower reaches of the 


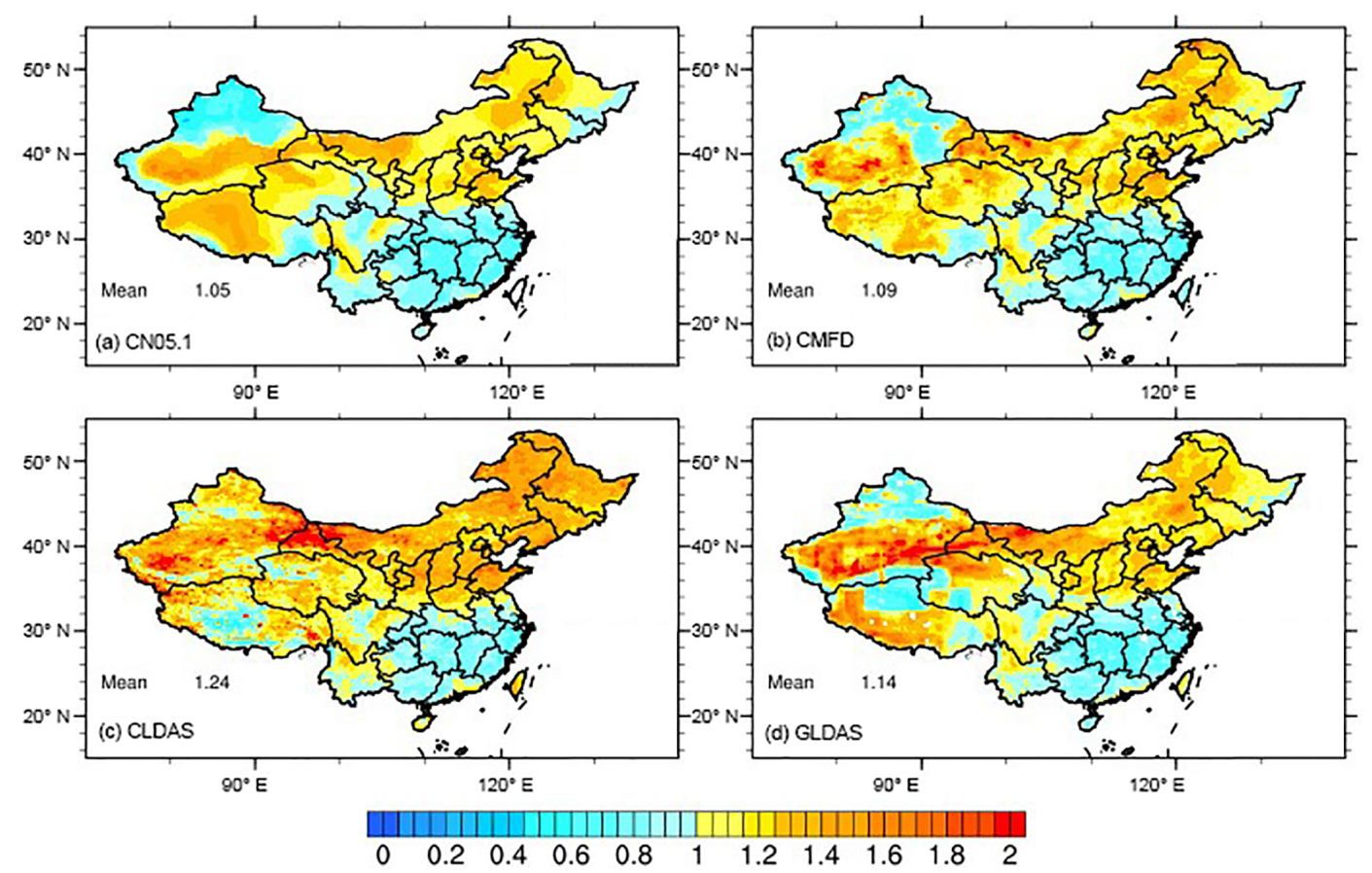

Figure 5. Distribution of TCV for precipitation products from (a) CN05.1, (b) CMFD, (c) CLDAS and (d) GLDAS during $2008-2014$.

Yangtze River (red polygon in Fig. 3). We therefore use independent MWR gauge-based observation data to further evaluate the forcing data sets in this region. As shown in Fig. 6, annual mean estimates of precipitation based on CMFD and CLDAS are more consistent with the MWR observations according to the RMSE and bias metrics. Comparison of MWR data with GLDAS and CN05.1 precipitation estimates shows RMSE values that are about twice as large as those for CLDAS. For GLDAS, the large RMSE appears to result primarily from a poor representation of the spatial variability in this region, as indicated by greater dispersion in the scatter plot. For CN05.1, the large RMSE results instead from a systematic high bias in annual mean precipitation throughout Hubei, Hunan and Jiangxi provinces. Monthly variations in bias and RMSE for these four data sets during 2014 are listed in Table 4. Based on these metrics, CLDAS provided the most accurate estimates of precipitation in this region during most months of 2014. A Taylor diagram based on these data (Fig. 7) confirms that CLDAS performed well during this year, as the orange points representing CLDAS are concentrated together in a region with correlation coefficients between 0.6 and 0.9 and normalized variance close to 1 , indicating low values of unbiased RMSE. These results indicate that monthly precipitation based on CLDAS is stable and reliable in this region. The performance of the other three data sets varies greatly from month to month, with particularly wide spreads for CMFD and CN05.1.

\section{Evaluation of shortwave radiation data}

\subsection{Comparison against ground measurements}

We compare the forcing data sets against station observations to evaluate their ability to reproduce the ground observations (Fig. 8). The CMFD data set compares well with station observations from CMA (Fig. 8a), while CLDAS (Fig. 8d) and GLDAS (Fig. 8g) are biased high relative to the station observations at about $96 \%$ of the validation points. This conclusion is supported by a Taylor diagram based on these data (Fig. 9), which shows that CMFD is highly correlated with a similar variance and an extremely small unbiased RMSE relative to the CMA stations. Based on the same metrics, CLDAS performs slightly better than GLDAS in reproducing observed shortwave radiation fluxes. Although these results strongly suggest that estimates of shortwave radiation from CMFD are more realistic than those from CLDAS or GLDAS, their significance is called into question by the cross-dependence between these site observations and the CMFD shortwave radiation product (Sect. 2.2.2). To account for this problem, we also use station observations from CERN that are completely independent of all three forcing data sets. The results of this comparison are similar to those of the previous comparison. Shortwave radiation products from CMFD (Fig. 8b) coincide well with the observations, while most shortwave radiation products from CLDAS (Fig. 8e) and GLDAS (Fig. 8h) generally overestimate the observed fluxes. Figure 9 likewise indicates that CMFD outperforms CLDAS and GLDAS with respect to spatiotem- 

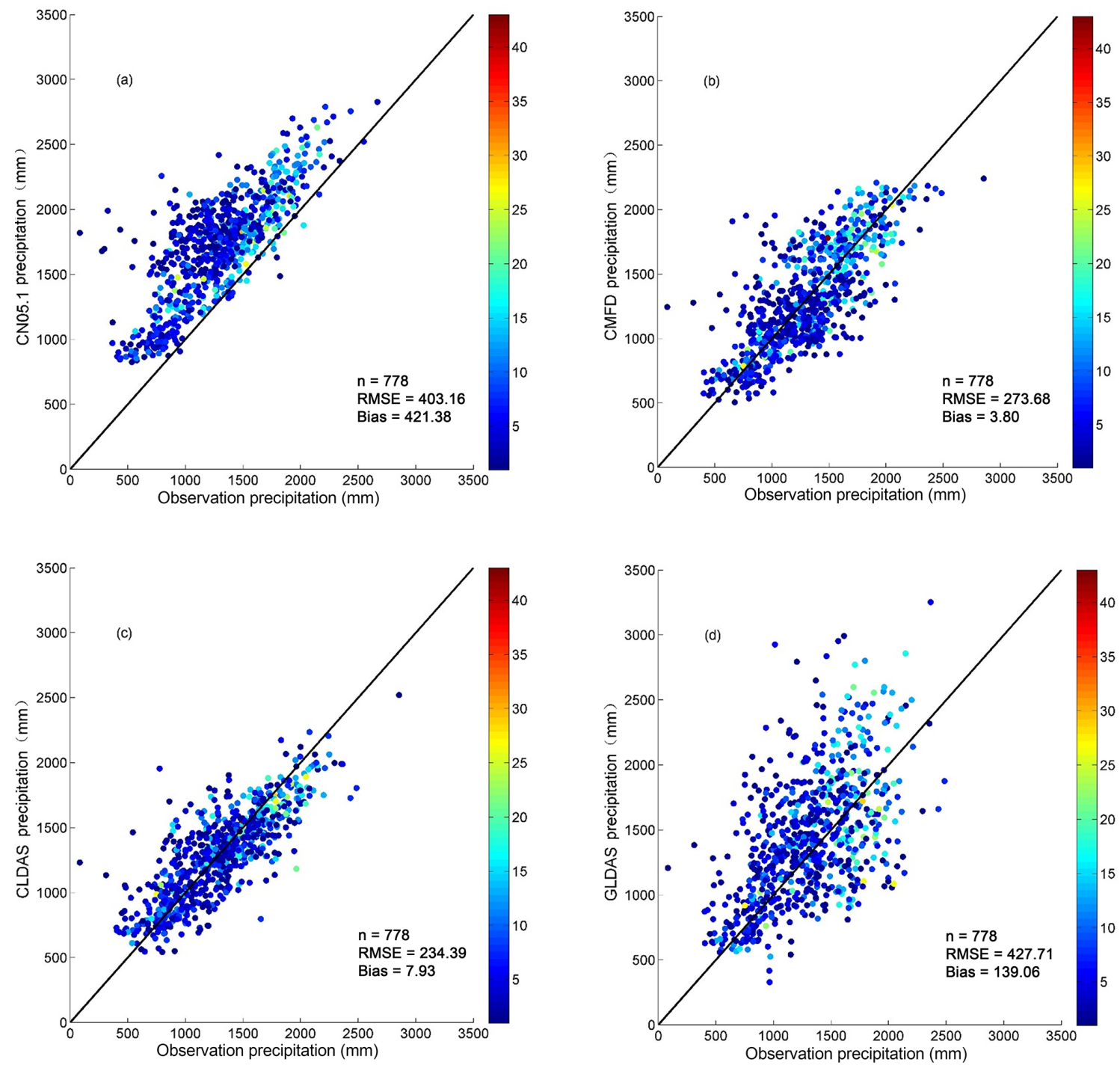

Figure 6. Comparison of the precipitation from (a) CN05.1, (b) CMFD, (c) CLDAS and (d) GLDAS against mutually independent rain gauge observations from MWR. The color bar on the right indicates the number of MWR rain gauges in the corresponding $0.25^{\circ} \times 0.25^{\circ}$ grid cell.

poral variability in these areas, while CLDAS outperforms GLDAS

As the CMA and CERN observation stations are relatively sparsely distributed in western China, we also validate the forcing data sets against observations of shortwave radiation at eight observation stations in the Heihe River basin and two observation stations in western Tibetan Plateau. CMFD (Fig. 8c) again provides the closest match with the in situ observations, while CLDAS (Fig. 8f) and GLDAS (Fig. 8i) again overestimate the observed fluxes. The Taylor diagram (Fig. 9) indicates that the three forcing data sets reproduce the spatiotemporal variability at these locations comparably well, although CLDAS produces a slightly smaller unbiased RMSE than the other two data sets and GLDAS shows the worst agreement with the observed values in all three metrics (correlation, normalized variance and unbiased RMSE). The RMSE and relative bias in the mean values at the station locations are substantially larger for CLDAS and GLDAS than for CMFD, but GLDAS produces the largest linear correlation coefficient between mean values at the station locations. These results are consistent with those of previous studies. Wang et al. (2011) showed that GLDAS estimates of shortwave radiation at the Changchun, Shenyang and Yanji stations in China were consistently too large during 2000-2006, while Qi et al. (2015) reported that GLDAS systematically overestimated surface shortwave radiation fluxes in the Biliu Basin (in the coastal region of northern China) from March 2000 to December 2007. 


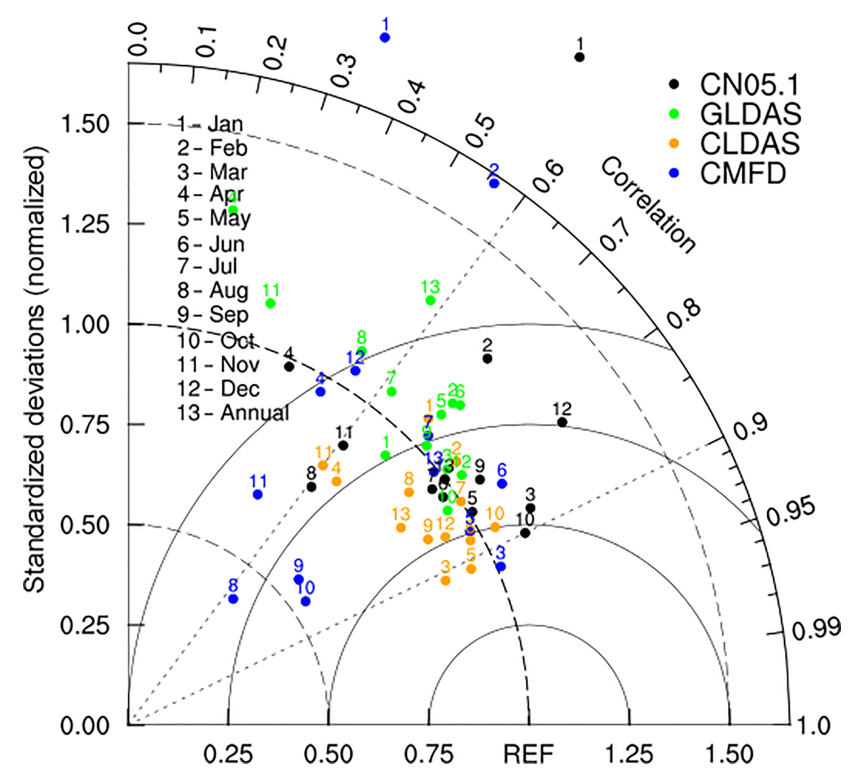

Figure 7. Taylor diagram summarizing the performance of monthly and annual mean precipitation from CN05.1 (black), CMFD (blue), CLDAS (orange) and GLDAS (green) relative to mutually independent rain gauge observations from MWR.

\subsection{Spatial distribution of shortwave radiation}

As discussed in the previous section, the shortwave radiation fluxes provided by CMFD correspond well with stationbased observations. We therefore use CMFD as a reference data set to evaluate the broader performance of CLDAS and GLDAS within major land areas of China.

As shown in Fig. 10, the spatial distributions of shortwave radiation fluxes based on the three forcing data sets have several common characteristics. Surface shortwave radiation is consistently greater in western China than in eastern China, with the largest shortwave radiation fluxes located over the Tibetan Plateau and relatively small shortwave radiation fluxes in northeastern China. Based on CMFD (Fig. 10a), the regions where surface shortwave radiation exceeds $200 \mathrm{~W} \mathrm{~m}^{-2}$ are limited to seven provinces: Xinjiang, Inner Mongolia, Qinghai, Tibet, Sichuan and Yunnan. Except for Tibet and Qinghai, these areas are relatively small. By contrast, both CLDAS and GLDAS indicate that the areas where shortwave radiation exceeds $200 \mathrm{~W} \mathrm{~m}^{-2}$ extend into northern China, and particularly Hebei and Shandong provinces. In GLDAS, fluxes exceeding $200 \mathrm{~W} \mathrm{~m}^{-2}$ even appear in southeastern China. Area-mean fluxes based on CLDAS and GLDAS are likewise larger than those based on CMFD, although the latter contains more spatial heterogeneity as indicated by larger values of SD and CV (Table 5).

Spatial distributions of the differences among the forcing data sets are shown in Fig. 11. Surface shortwave radiation fluxes based on CLDAS and GLDAS are much larger than those based on CMFD over most parts of China. Pos-
Table 5. Statistical metrics describing the spatial average and variability of annual mean shortwave radiation during 2008-2014, along with the average difference, RMSE, bias and correlation coefficient relative to CMFD.

\begin{tabular}{lrrr}
\hline Metrics & CMFD & CLDAS & GLDAS \\
\hline Mean $\left(\mathrm{W} \mathrm{m}^{-2}\right)$ & 178.60 & 202.26 & 203.13 \\
$\mathrm{SD}\left(\mathrm{W} \mathrm{m}^{-2}\right)$ & 31.13 & 28.82 & 20.99 \\
$\mathrm{CV}$ & 0.17 & 0.14 & 0.10 \\
Average difference $\left(\mathrm{W} \mathrm{m}^{-2}\right)$ & - & 23.72 & 24.57 \\
RMSE $\left(\mathrm{W} \mathrm{m}^{-2}\right)$ & - & 27.55 & 28.61 \\
Relative bias & - & 0.14 & 0.15 \\
Correlation coefficient & - & 0.89 & 0.92 \\
\hline
\end{tabular}

itive differences between CLDAS and CMFD cover more than $95 \%$ of the area of major land areas of China, with particularly pronounced estimates in some areas of Xinjiang Province and the area bounded by $24-44^{\circ} \mathrm{N}$ and $105-120^{\circ} \mathrm{E}$. Estimates of surface shortwave radiation from GLDAS are also significantly higher than those from CMFD except for over the Tibetan Plateau. The statistical metrics listed in Table 5 show similar absolute values for the average difference, RMSE and relative bias, although the differences between CLDAS and CMFD are slightly less than those between GLDAS and CMFD for all three metrics. Correlation coefficients between the three forcing data sets are consistently around 0.9 . Overall, CLDAS and GLDAS are similar, with overestimates relative to CMFD in most regions of major land areas of China.

\subsection{Temporal variations in shortwave radiation}

Figure 12 shows time series of shortwave radiation anomalies averaged over mainland China. CMFD and CLDAS generally match each other well, particularly during the middle part of the record, but with different amplitudes of month-tomonth variations. GLDAS indicates the largest fluctuations relative to the mean annual cycle among these three data sets. The absolute difference between GLDAS and CMFD exceeds that between CLDAS and CMFD in 52 of 84 months. CLDAS consistently shows positive anomalies after year 2013 and primarily shows negative anomalies before January 2011. These changes suggest a potential drift relative to the climatological annual cycle during the analysis period. No such drift is evident in CMFD. Mean shortwave radiation from GLDAS was also consistently larger than its climatological annual cycle through most of 2012-2014. Table 6 summarizes the temporal variations in shortwave radiation based on CLDAS and GLDAS relative to CMFD. The two data sets perform comparably with respect to CMFD based on these summary statistics, with CLDAS showing slightly smaller values of RMSE and bias and GLDAS showing a slightly higher correlation relative to CMFD. 

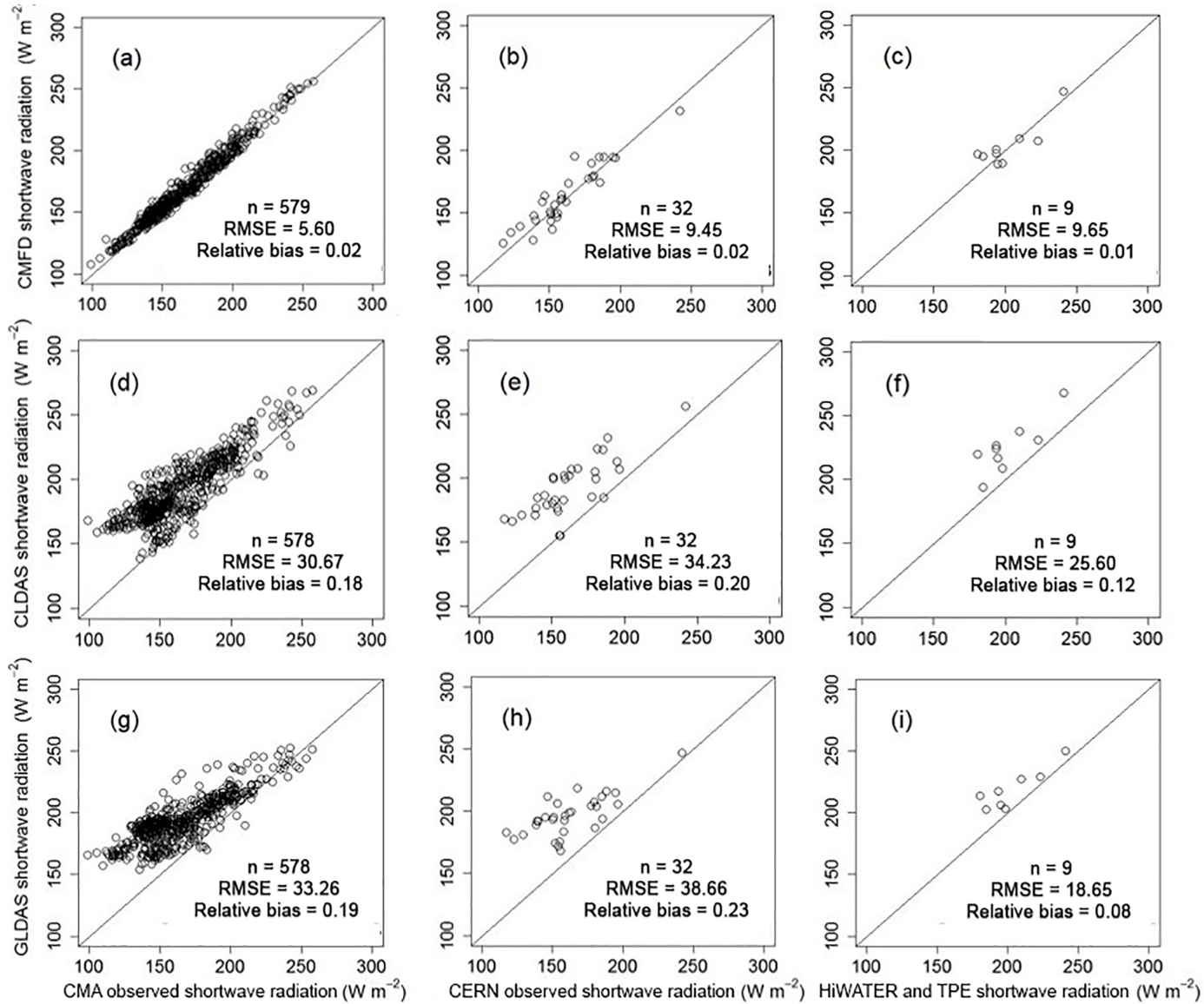

Figure 8. Relationships between shortwave radiation from forcing data and shortwave radiation based on station observations.

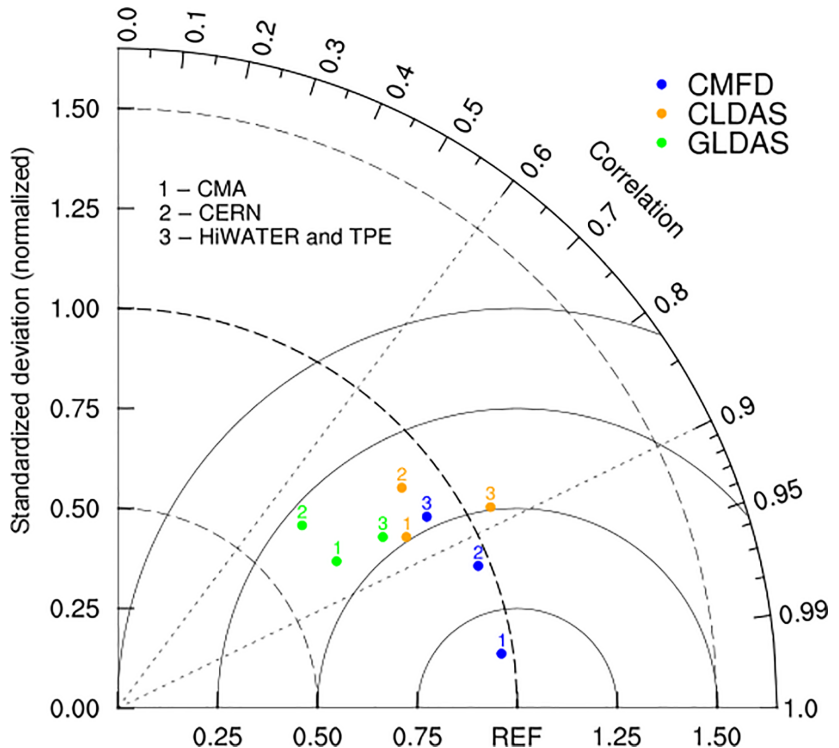

Figure 9. Taylor diagram summarizing the performance of shortwave radiation estimates from CMFD (blue), CLDAS (orange) and GLDAS (green) relative to station observations.
Table 6. Statistical metrics for monthly mean shortwave radiation anomalies among forcing data sets during 2008-2014.

\begin{tabular}{lrr}
\hline Metrics & CLDAS-CMFD & GLDAS-CMFD \\
\hline RMSE $\left(\mathrm{W} \mathrm{m}^{-2}\right)$ & 5.14 & 5.79 \\
Relative bias & 1.14 & 1.66 \\
Correlation coefficient & 0.50 & 0.62 \\
\hline
\end{tabular}

The spatial pattern of TCV for shortwave radiation of the three forcing data sets have some common characteristics: the highest TCV appears in northwest and northeast China while the smallest TCV can be found in southwest China. For south of $34^{\circ} \mathrm{N}$, the TCV of CLDAS is lower than 0.25 while CMFD is higher than 0.25 in the southeast. In addition, the estimation of TCV in CMFD and GLDAS has an obviously higher value in the vicinity of Sichuan Province and Chongqing Province than the surrounding areas. The TCV values of the three data sets are similar to each other north of $34^{\circ} \mathrm{N}$ and the difference mainly lies in the south of China. The characteristics mentioned above are shown in Fig. 13. 

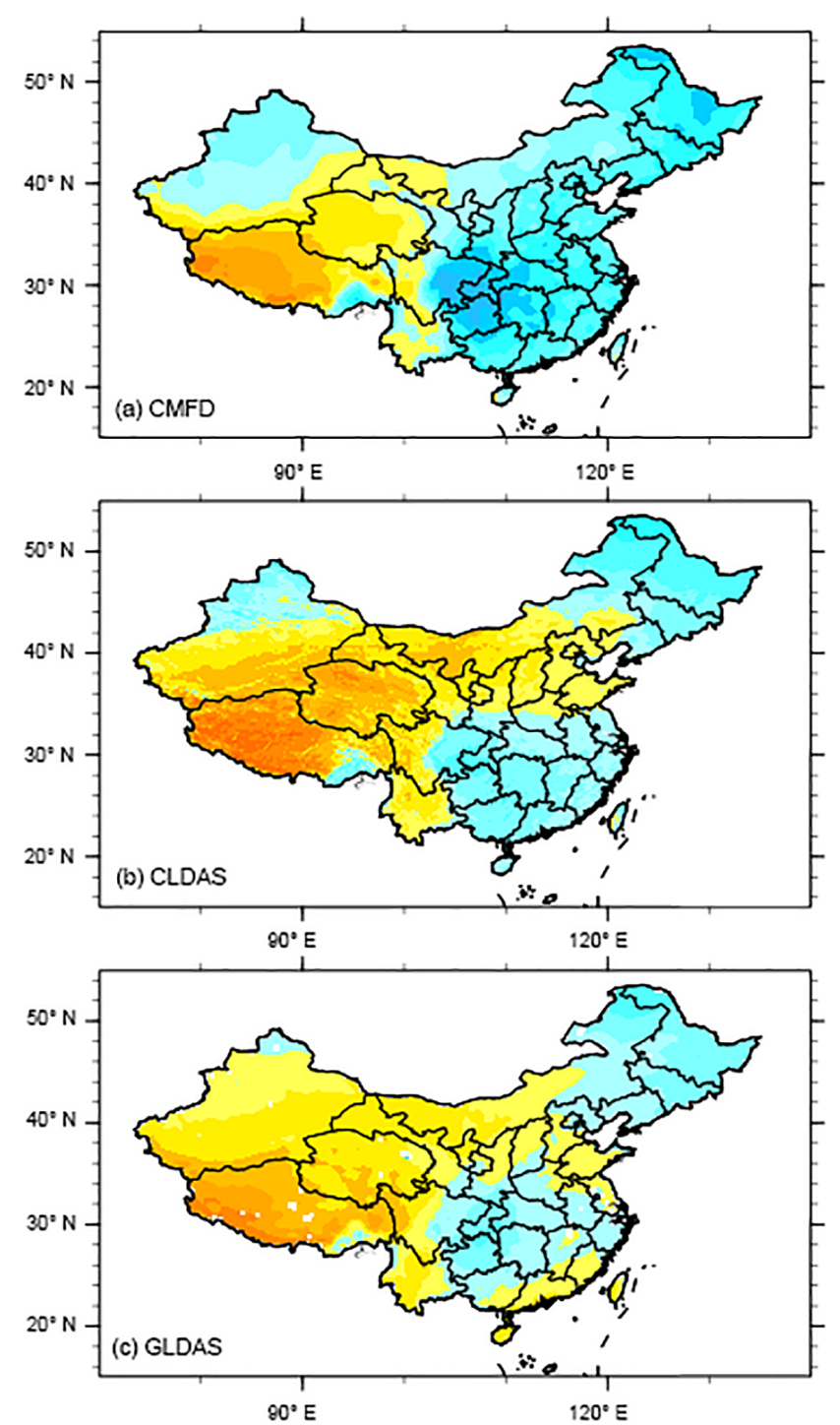

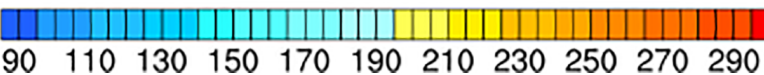

Figure 10. Spatial distributions of annual-mean shortwave radiation based on the three forcing data sets over 2008-2014 (unit: $\mathrm{W} \mathrm{m}^{-2}$ ).

\section{Discussion}

Although these forcing data sets have many characteristics in common and can accurately reflect the broad features of precipitation and shortwave radiation over major land areas of China, our analysis identifies many important differences. These differences arise from multiple factors, including different resolutions, different underlying data and different algorithms for combining those data.

We have compared the spatial distributions of precipitation in the forcing data sets and evaluated their quality in the middle and lower reaches of the Yangtze River. CLDAS performs better at both annual and monthly timescales because it merges observations from more than 30000 stations, which has substantial benefits for the quality of the analysis. CMFD is able to reproduce annual mean values, but is less realistic at monthly scales. The sharp decrease in the CMFD precipitation analysis after August 2014 is particularly surprising. Relative to CN05.1 and CLDAS, CMFD used fewer precipitation observations from a smaller selection of stations, which may influence the quality of its analysis in 2014. GLDAS is a global data set. The accuracy of this data set in major land areas of China may thus be limited by a dearth of assimilated observations in China. Although both CMFD and GLDAS use remote sensing data as the initial background state, they differ considerably due to differences in both the satellite data and the station data they use. CN05.1 was constructed solely from station data based on a mathematical interpolation. It is therefore reasonable that CN05.1 does not perform as well as the other forcing data sets in regions where stations are sparse.

With respect to shortwave radiation, we find that CMFD significantly outperforms CLDAS and GLDAS. Only about 100 sparsely distributed radiation stations have been deployed in China since 1961, and the radiation observations reported by these stations are often unusable due to erroneous values or missing data (Shi et al., 2008). The observations of surface solar radiation available for merging into CLDAS and GLDAS are therefore limited. By contrast, CMFD assimilated a 50-year reconstruction of daily surface solar radiation at 716 CMA stations (Sect. 2.1.2). Although these data are based on model outputs, they have been widely validated and show good performance throughout China. The shortwave radiation products provided by CMFD are therefore in better agreement with direct observations.

\section{Conclusions}

In recent years, an increasing number of forcing data sets have been developed to support climatological, agricultural and hydrological research. In this study, we have presented an intercomparison and evaluation of precipitation and shortwave radiation products from the CN05.1, CMFD, CLDAS and GLDAS forcing data sets over major land areas of China. The results provide useful guidance to the users and producers of these data sets.

For precipitation, all four forcing data sets show similar spatial distributions, with a positive gradient in precipitation from northwestern China to southeastern China. Precipitation estimates from CLDAS are systematically smaller than those from the other data sets in most areas of China. The temporal variability of monthly mean precipitation anomalies is generally consistent among the four forcing data sets, except for a sudden decrease in CMFD precipitation after August 2014. The spatial distribution of temporal variability (as represented by TCV) is inversely related to the spatial distribution of precipitation amount, with larger variability in dry regions than in wet regions. Variability is also larger in 

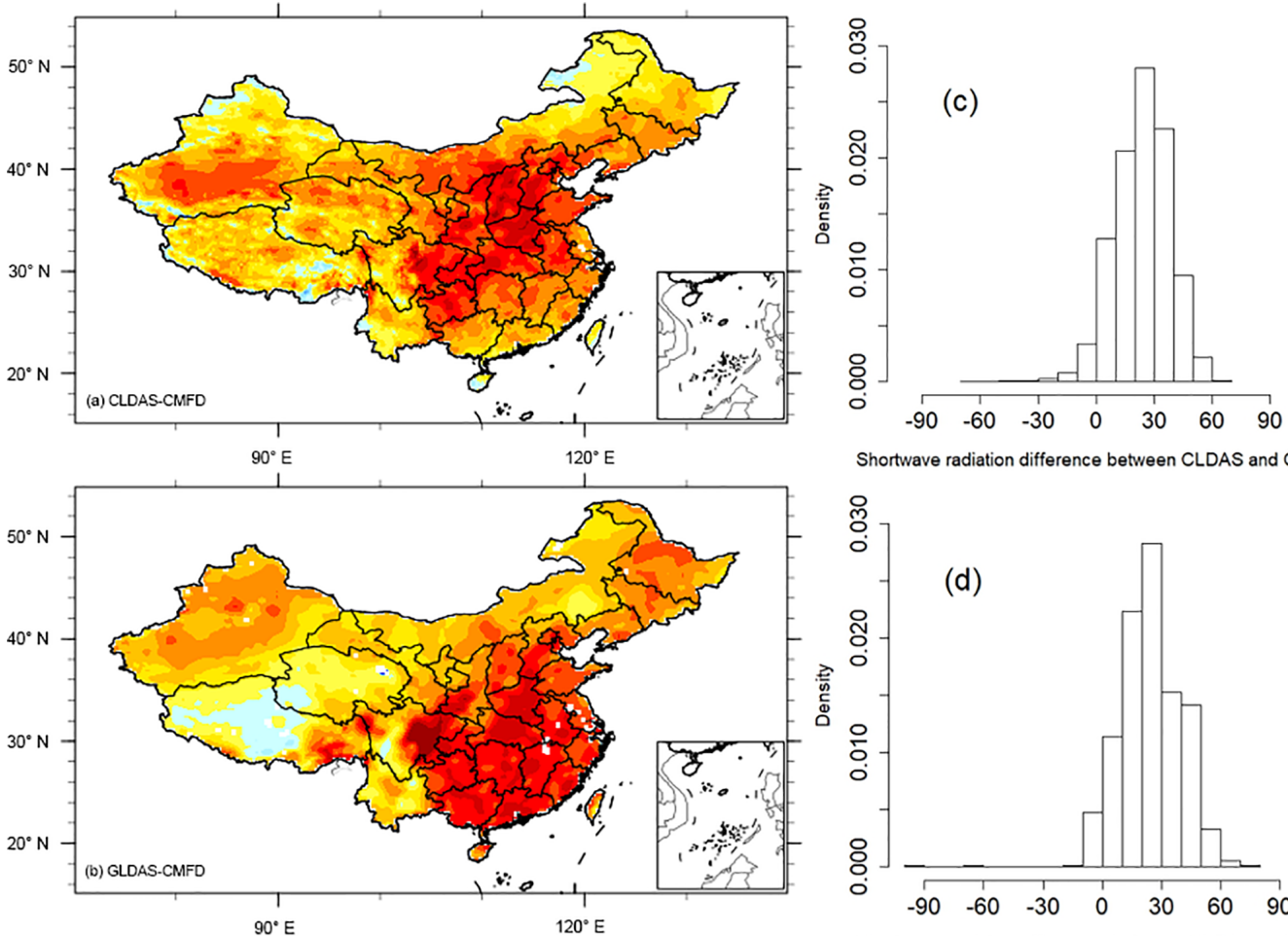

Shortwave radiation difference between CLDAS and CMFD

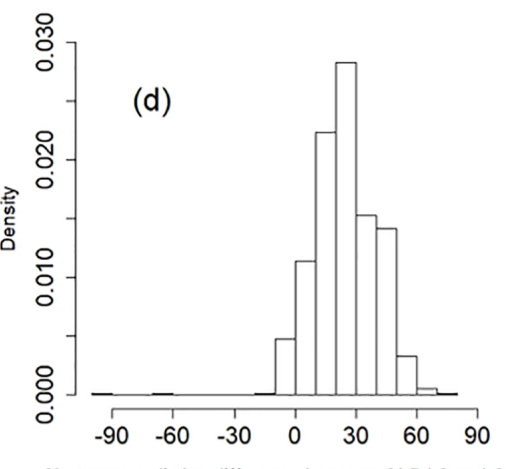

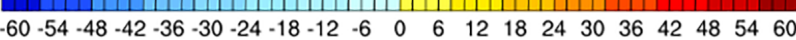

Shortwave radiation difference between GLDAS and CMFD

Figure 11. Spatial distributions of differences in mean shortwave radiation between (a) CLDAS and CMFD and (b) GLDAS and CMFD. The corresponding histograms are shown in (c) for CLDAS-CMFD and (d) for GLDAS-CMFD.

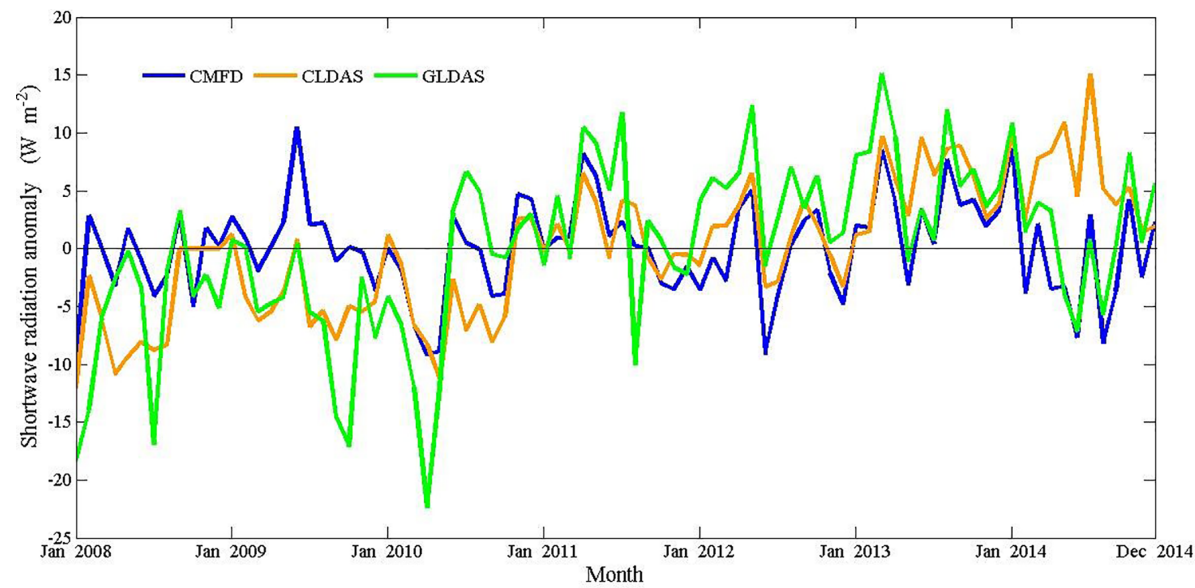

Figure 12. Time series of monthly mean shortwave radiation anomalies relative to the mean annual cycle from CMFD (blue), CLDAS (orange) and GLDAS (green; unit: $\mathrm{W} \mathrm{m}^{-2}$ ).

CLDAS than in the other data sets, as is the area where TCV exceeds 1.0. We have validated the forcing data sets against independent rain gauge observations provided by MWR for the middle and lower reaches of the Yangtze River valley during 2014. Based on this validation, CLDAS provides the best performance at both annual and monthly timescales, with the lowest RMSE and highest correlation coefficient among the four forcing data sets. CMFD provides good estimates of annual mean precipitation at the MWR stations, but this agreement is considerably reduced at monthly timescales. CN05.1 greatly overestimates precipitation in this region relative to the MWR observations.

For shortwave radiation, comparisons against groundbased observations show that both CLDAS and GLDAS sub- 

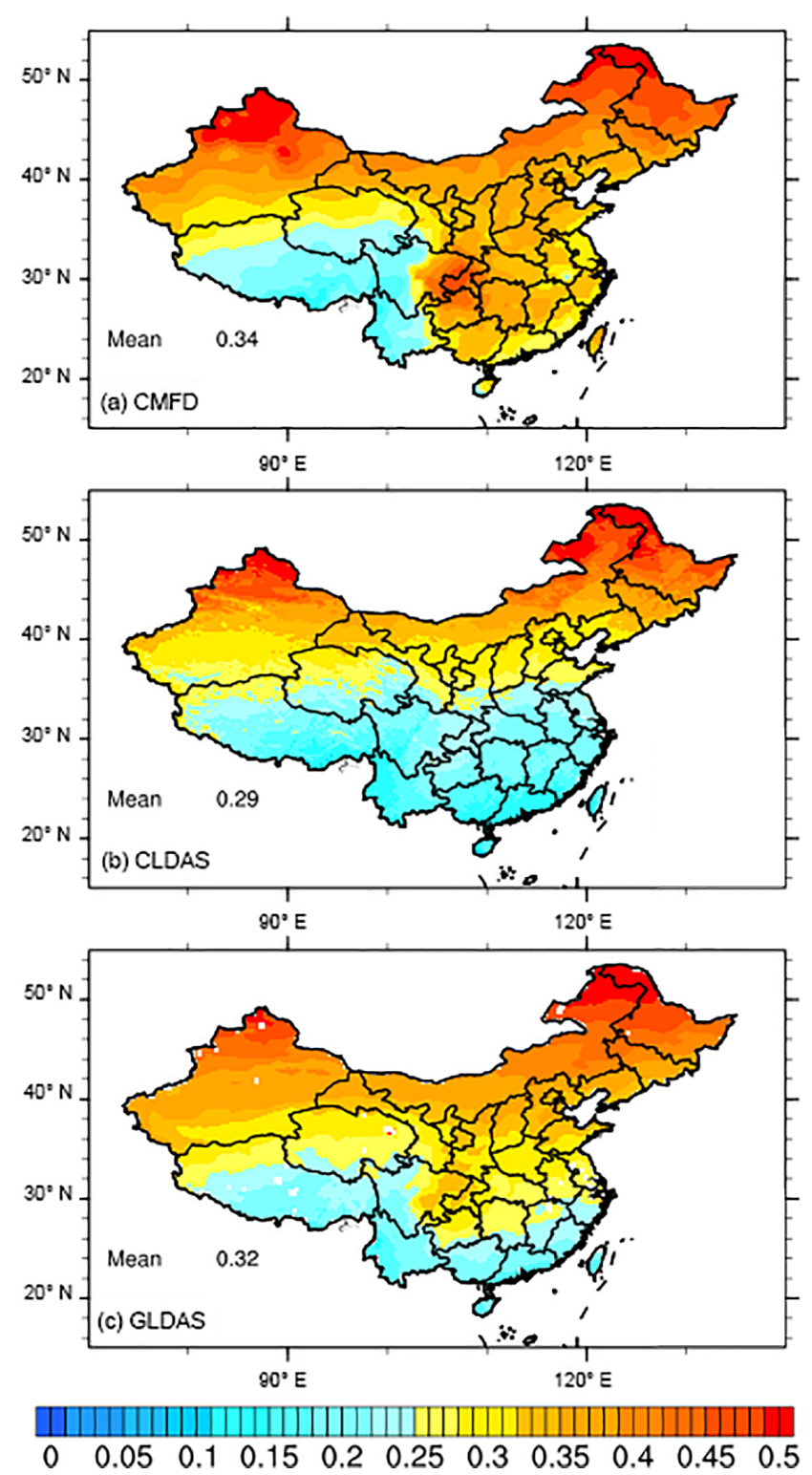

Figure 13. Spatial distributions of TCV for shortwave radiation products from the three forcing data sets.

stantially overestimate shortwave radiation. These data also have much higher RMSEs and biases relative to direct observations, and relatively low correlation coefficients. CLDAS slightly outperforms GLDAS; however, CMFD significantly outperforms both with respect to the validation data. All forcing data sets capture the key features of the spatial distribution of shortwave radiation, with higher values in western China than eastern China and the largest values centered over the Tibetan Plateau. The spatial characteristics of CLDAS and GLDAS are especially similar, with both data sets indicating much larger shortwave fluxes than CMFD in most parts of major land areas of China. Differences between CLDAS and CMFD are generally smaller than those between
GLDAS and CMFD. Time series of anomalies in area-mean shortwave radiation averaged over China show large fluctuations in GLDAS and a gradual drift in CLDAS. Estimates from CMFD are more stable. Temporal variability in the three forcing data sets is more similar north of $34^{\circ} \mathrm{N}$, with larger differences in the south. All three data sets indicate that shortwave radiation is more variable over northern China than over southern China.

In summary, none of these data sets clearly outperforms the others with respect to both precipitation and shortwave radiation. CLDAS, which has the highest spatial and temporal resolution, appears to provide the most realistic estimates of precipitation. However, this data set also considerably overestimates shortwave radiation. CMFD is also available at high resolution, and its estimates of shortwave radiation data match well with station-based observations. Its estimates of annual mean precipitation are also reliable, but this reliability at annual timescales masks relatively large errors in monthly precipitation. GLDAS estimates of both precipitation and shortwave radiation over major land areas of China have considerable room for improvement, as do CN05.1 estimates of precipitation, particularly in regions where station data are sparse. These products are widely used and continually being developed and improved. Our results will help researchers to make more informed decisions when selecting data, contribute to uncertainty quantification and provide guidelines that can help data providers to improve these data sets and others like them. Our results also highlight the large uncertainties that remain in currently available forcing data, especially in western China, where the density of ground stations is low. There is a great need to improve the quality of forcing data in this region.

Data availability. CMFD can be downloaded through https://doi.org/10.3972/westdc.002.2014.db (He and Yang, 2011). CLDAS (Shi et al., 2014) is provided by the China Meteorological Data Sharing Service System (http://data.cma.cn/data/detail/dataCode/NAFP_CLDAS2.0_

NRT/keywords/CLDAS.html). GLDAS can be downloaded through https://doi.org/10.5067/7NP2052IA62C (Rodell et al., 2004). CN05.1 (Wu and Gao, 2013) and MWR (Xu et al., 2017) data are available upon request to the corresponding author. CMA shortwave radiation data are provided by the Data Assimilation and Modeling Center for Tibetan Multi-spheres (http://dam.itpcas.ac.cn/data/daily_solar_radiation_dataset_over_ China_readme.htm; Tang et al., 2013). Shortwave radiation data from CERN are provided by the Chinese Ecosystem Research Network through http://cerndis1.cern.ac.cn/data/meta?id=17046 (Su et al., 2005). Shortwave radiation data from HiWATER are provided by Heihe Watershed Allied Telemetry Experimental Research (HiWATER; Li et al., 2013), and users can download the data from http://www.heihedata.org/data/. Shortwave radiation data from TPE are provided by the Third Pole Environment Database (https://doi.org/10.11888/AtmosphericPhysics.tpe.62.db and https://doi.org/10.11888/Hydrology.tpe.249426.db). 
Competing interests. The authors declare that they have no conflict of interest.

Acknowledgements. This work was jointly supported by the National Basic Research Program of China (no. 2015CB953703), the National Natural Science Foundation of China (91537210 \& 41371328) and the National Key Research and Development Program of China (2016YFA0601603). We are grateful to Xuejie Gao at IAP for providing CN05.1 and to Chunxiang Shi at CMA for providing CLDAS. The GLDAS data used in this study were acquired as part of the mission of NASA's Earth Science Division and archived and distributed by the Goddard Earth Sciences (GES) Data and Information Services Center (DISC). The authors also wish to thank the Third Pole Environment Database, CERN Database and HiWATER Project for provide shortwave radiation station data. The computation for this work is supported by Tsinghua National Laboratory for Information Science and Technology. We acknowledge reviewers for their insightful and constructive comments which improved the manuscript substantially.

Edited by: Fuqiang Tian

Reviewed by: three anonymous referees

\section{References}

Bart, N. and Lettenmaier, D. P.: Effect of precipitation sampling error on simulated hydrological fluxes and states: Anticipating the Global Precipitation Measurement satellites, J. Geophys. Res.Atmos., 109, 265-274, https://doi.org/10.1029/2003JD003497, 2004.

Boegh, E., Thorsen, M., Butts, M. B., Hansen, S., Christiansen, J. S., Abrahamsen, P., Hasager, C. B., Jensen, N. O., van der Keur, P., Refsgaard, J. C., Schelde, K., Soegaard, H., and Thomsen, A.: Incorporating remote sensing data in physically based distributed agro-hydrological modelling, J. Hydrol., 287, 279-299, https://doi.org/10.1016/j.jhydrol.2003.10.018, 2004.

Chen, Y. Y., Yang, K., He, J., Qin, J., Shi, J. C., Du, J. Y., and $\mathrm{He}, \mathrm{Q}$.: Improving land surface temperature modeling for dry land of China, J. Geophys. Res.-Atmos., 116, D20104, https://doi.org/10.1029/2011jd015921, 2011.

Chen, Y. Y., Yang, K., Qin, J., Zhao, L., Tang, W. J., and Han, M. L.: Evaluation of AMSR-E retrievals and GLDAS simulations against observations of a soil moisture network on the central Tibetan Plateau, J. Geophys. Res.-Atmos., 118, 4466-4475, https://doi.org/10.1002/jgrd.50301, 2013.

Cheng, G. D., Li, X., Zhao, W. Z., Xu, Z. M., Feng, Q., Xiao, S. C., and Xiao, H. L.: Integrated study of the water-ecosystemeconomy in the Heihe River Basin, Nat. Sci. Rev., 1, 413-428, https://doi.org/10.1093/nsr/nwu017, 2014.

Cosgrove, B. A., Lohmann, D., Mitchell, K. E., Houser, P. R., Wood, E. F., Schaake, J. C., Robock, A., Marshall, C., Sheffield, J., Duan, Q. Y., Luo, L. F., Higgins, R. W., Pinker, R. T., Tarpley, J. D., and Meng, J.: Real-time and retrospective forcing in the North American Land Data Assimilation System (NLDAS) project, J. Geophys. Res.-Atmos., 108, 1887-1902, https://doi.org/10.1029/2002jd003118, 2003.
Dee, D. P., Uppala, S. M., Simmons, A. J., Berrisford, P., Poli, P., Kobayashi, S., Andrae, U., Balmaseda, M. A., Balsamo, G., Bauer, P., Bechtold, P., Beljaars, A. C. M., van de Berg, L., Bidlot, J., Bormann, N., Delsol, C., Dragani, R., Fuentes, M., Geer, A. J., Haimberger, L., Healy, S. B., Hersbach, H., Holm, E. V., Isaksen, L., Kallberg, P., Kohler, M., Matricardi, M., McNally, A. P., Monge-Sanz, B. M., Morcrette, J. J., Park, B. K., Peubey, C., de Rosnay, P., Tavolato, C., Thepaut, J. N., and Vitart, F.: The ERA-Interim reanalysis: configuration and performance of the data assimilation system, Q. J. Roy. Meteor. Soc., 137, 553-597, https://doi.org/10.1002/qj.828, 2011.

Duan, Z., Bastiaanssen, W. G. M., and Liu, J.: Monthly and annual validation of TRMM Mulitisatellite Precipitation Analysis (TMPA) products in the Caspian Sea Region for the period 19992003, Geoscience and Remote Sensing Symposium, 3696-3699, https://doi.org/10.1109/igarss.2012.6350613,2012.

Fekete, B. M., Vorosmarty, C. J., Roads, J. O., and Willmott, C. J.: Uncertainties in precipitation and their impacts on runoff estimates, J. Climate, 17, 294-304, https://doi.org/10.1175/15200442(2004)017<0294:Uipati>2.0.Co;2, 2004.

Gao, X. J., Wang, M. L., and Giorgi, F.: Climate Change over China in the 21st Century as Simulated by BCC_CSM1.1RegCM4.0, Atmospheric and Oceanic Science Letters, 6, 381386, https://doi.org/10.3878/j.issn.1674-2834.13.0029,2013.

Gottschalck, J., Meng, J., Rodell, M., and Houser, P.: Analysis of multiple precipitation products and preliminary assessment of their impact on global land data assimilation system land surface states, J. Hydrometeorol., 6, 573-598, https://doi.org/10.1175/Jhm437.1, 2005.

Guo, D. and Wang, H.: Simulation of permafrost and seasonally frozen ground conditions on the Tibetan Plateau, 1981-2010, J. Geophys. Res.-Atmos., 118, 5216-5230, https://doi.org/10.1002/jgrd.50457, 2013.

Han S.: The simulation and evaluation using CLM3.5 and SSIB2 land surface model based CLDAS forcing data with drought monitoring. Nanjing University of Information Science and Technology, 2015.

He, J. and Yang, K.: China Meteorological Forcing Dataset. Cold and Arid Regions Science Data Center, Lanzhou, https://doi.org/10.3972/westdc.002.2014.db, 2011.

Hu, Z. D., Wang, L., Wang, Z. J., Hong, Y., and Zheng, H.: Quantitative assessment of climate and human impacts on surface water resources in a typical semi-arid watershed in the middle reaches of the Yellow River from 1985 to 2006, Int. J. Climatol., 35, 97 113, https://doi.org/10.1002/joc.3965, 2015.

Huang, J. P., Yu, H. P., Guan, X. D., Wang, G. Y., and Guo, R. X.: Accelerated dryland expansion under climate change, Nature Climate Change, 6, 166-172, https://doi.org/10.1038/Nclimate2837, 2016.

Huang, Y., Salama, M. S., Krol, M. S., van der Velde, R., Hoekstra, A. Y., Zhou, Y., and Su, Z.: Analysis of long-term terrestrial water storage variations in the Yangtze River basin, Hydrol. Earth Syst. Sci., 17, 1985-2000, https://doi.org/10.5194/hess-17-19852013, 2013.

Huang, Y., Wang, H., Fan, K., and Gao, Y.: The western Pacific subtropical high after the 1970s: westward or eastward shift?, Clim. Dynam., 44, 2035-2047, https://doi.org/10.1007/s00382014-2194-5, 2015. 
Kalnay, E., Kanamitsu, M., Kistler, R., Collins, W., Deaven, D., Gandin, L., Iredell, M., Saha, S., White, G., Woollen, J., Zhu, Y., Chelliah, M., Ebisuzaki, W., Higgins, W., Janowiak, J., Mo, K. C., Ropelewski, C., Wang, J., Leetmaa, A., Reynolds, R., Jenne, R., and Joseph, D.: The NCEP/NCAR 40-year reanalysis project, B. Am. Meteorol. Soc., 77, 437-471, https://doi.org/10.1175/15200477(1996)077<0437:Tnyrp>2.0.Co;2, 1996.

Kang, L. T., Huang, J. P., Chen, S. Y., and Wang, X.: Long-term trends of dust events over Tibetan Plateau during 1961-2010, Atmos. Environ., 125, 188-198, https://doi.org/10.1016/j.atmosenv.2015.10.085, 2016.

Kobayashi, S., Ota, Y., Harada, Y., Ebita, A., Moriya, M., Onoda, H., Onogi, K., Kamahori, H., Kobayashi, C., Endo, H., Miyaoka, K., and Takahashi, K.: The JRA-55 Reanalysis: General Specifications and Basic Characteristics, J. Meteorol. Soc. Jpn., 93, 5-48, https://doi.org/10.2151/jmsj.2015-001, 2015.

Li, X., Cheng, G. D., Liu, S. M., Xiao, Q., Ma, M. G., Jin, R., Che, T., Liu, Q. H., Wang, W. Z., Qi, Y., Wen, J. G., Li, H. Y., Zhu, G. F., Guo, J. W., Ran, Y. H., Wang, S. G., Zhu, Z. L., Zhou, J., Hu, X. Li, and Xu, Z. W.: Heihe watershed allied telemetry experimental research (HiWATER): Scientific objectives and experimental design, B. Am. Meteorol. Soc., 94, 11451160, https://doi.org/10.1175/BAMS-D-12-00154.1, 2013.

Liu, S. M., Xu, Z. W., Song, L. S., Zhao, Q. Y., Ge, Y., Xu, T. R., Ma, Y. F., Zhu, Z. L., Jia, Z. Z., and Zhang, F.: Upscaling evapotranspiration measurements from multi-site to the satellite pixel scale over heterogeneous land surfaces, Agr. Forest Meteorol., 230, 97-113, https://doi.org/10.1016/j.agrformet.2016.04.008, 2016.

Luo, L. F., Robock, A., Mitchell, K. E., Houser, P. R., Wood, E. F., Schaake, J. C., Lohmann, D., Cosgrove, B., Wen, F. H., and Sheffield, J.: Validation of the North American Land Data Assimilation System (NLDAS) retrospective forcing over the southern Great Plains, J. Geophys. Res.-Atmos., 108, 8843, https://doi.org/10.1029/2002JD003246,2003.

Maurer, E. P., Wood, A. W., Adam, J. C., Lettenmaier, D. P., and Nijssen, B.: A long-term hydrologically based dataset of land surface fluxes and states for the conterminous United States, J. Climate, 15, 3237-3251, https://doi.org/10.1175/15200442(2002)015<3237:Althbd>2.0.Co;2, 2002.

New, M., Hulme, M., and Jones, P.: Representing twentiethcentury space-time climate variability. Part II: development of 1901-96 monthly grids of terrestrial surface climate, J. Climate, 13, 2217-2238, https://doi.org/10.1175/15200442(2000)013<2217:RTCSTC>2.0.CO;2 2000.

Pan, X. D., Li, X., and Chao, Z. H.: Review of Research of Forcing Data for Regional Scale Hydrological Model, Adv. Earth Sci., 25, 1314-1324, https://doi.org/10.11867/j.issn.10018166.2010.12.1314, 2010.

Pan, X. D., Li, X., Yang, K., He, J., Zhang, Y. L., and Han, X. J.: Comparison of Downscaled Precipitation Data over a Mountainous Watershed: A Case Study in the Heihe River Basin, J. Hydrometeorol., 15, 1560-1574, https://doi.org/10.1175/Jhm-D13-0202.1, 2014.

Qi, W., Zhang, C., Fu, G. T., and Zhou, H. C.: Global Land Data Assimilation System data assessment using a distributed biosphere hydrological model, J. Hydrol., 528, 652-667, https://doi.org/10.1016/j.jhydrol.2015.07.011, 2015.
Qian, T., Dai, A., Trenberth, K. E., and Oleson, K. W.: Simulation of Global Land Surface Conditions from 1948 to 2004. Part I: Forcing Data and Evaluations, J. Hydrometeorol., 7, 953-975, https://doi.org/10.1175/JHM540.1, 2006.

Rodell, M., Houser, P. R., Jambor, U., Gottschalck, J., Mitchell, K., Meng, C. J., Arsenault, K., Cosgrove, B., Radakovich, J., Bosilovich, M., Entin, J. K., Walker, J. P., Lohmann, D., and Toll, D.: The global land data assimilation system, B. Am. Meteorol. Soc., 85, 381-394, https://doi.org/10.1175/Bams-85-3-381, 2004.

Rui, H. and Beaudoing, H., 2017: Readme document for GLDAS version 1 Data Products, available at: https://hydro1.gesdisc. eosdis.nasa.gov/data/GLDAS_V1/README.GLDAS.pdf, last access: 30 September 2017.

Shen, M. G., Piao, S. L., Cong, N., Zhang, G. X., and Janssens, I. A.: Precipitation impacts on vegetation spring phenology on the Tibetan Plateau, Glob. Change Biol., 21, 3647-3656, https://doi.org/10.1111/gcb.12961, 2015.

Shen, Y., Zhao, P., Pan, Y., and Yu, J.: A high spatiotemporal gauge-satellite merged precipitation analysis over China, J. Geophys. Res.-Atmos., 119, 3063-3075, https://doi.org/10.1002/2013JD020686, 2014.

Shi, C., Xie, Z., Qian, H., Liang, M., and Yang, X.: China land soil moisture EnKF data assimilation based on satellite remote sensing data, Science Chine Earth Sciences, 54, 1430-1440, https://doi.org/10.1007/s11430-010-4160-3, 2011.

Shi, C., Jiang, L., Zhang, T., Xu, B., and Han, S.: Status and Plans of CMA Land Data Assimilation System (CLDAS) Project, EGU General Assembly Conference Abstracts, 2014.

Shi, G.-Y., Hayasaka, T., Ohmura, A., Chen, Z.-H., Wang, B., Zhao, J.-Q., Che, H.-Z., and Xu, L.: Data Quality Assessment and the Long-Term Trend of Ground Solar Radiation in China, J. Appl. Meteorol. Clim., 47, 1006-1016, https://doi.org/10.1175/2007JAMC1493.1,2008.

Su, W., Guo, X.-B., Yue, H.-L., and Yue, Y.-Z.: Web-based Management and Sharing System of CERN Observational Data, Journal of Agricultural Mechanization Research, 4, 220-223, https://doi.org/10.13427/j.cnki.njyi.2005.04.083, 2005.

Tang, Q. H., Oki, T., Kanae, S., and Hu, H. P.: Hydrological cycles change in the Yellow River basin during the last half of the twentieth century, J. Climate, 21, 1790-1806, https://doi.org/10.1175/2007jcli1854.1, 2008.

Tang, W. J., Yang, K., Qin, J., and Min, M.: Development of a 50-year daily surface solar radiation dataset over China, Science China-Earth Sciences, 56, 1555-1565, https://doi.org/10.1007/s11430-012-4542-9, 2013.

Taylor, K. E.: Summarizing multiple aspects of model performance in a single diagram, J. Geophys. Res.-Atmos., 106, 7183-7192, https://doi.org/10.1029/2000JD900719, 2001.

Tian, Y., Peters-Lidard, C. D., Choudhury, B. J., and Garcia, M.: Multitemporal analysis of TRMM-based satellite precipitation products for land data assimilation applications, J. Hydrometeorol., 8, 1165-1183, https://doi.org/10.1175/2007jhm859.1, 2007.

Wang, A. H. and Zeng, X. B.: Evaluation of multireanalysis products with in situ observations over the Tibetan Plateau, J. Geophys. Res.-Atmos., 117, 5102, https://doi.org/10.1029/2011jd016553, 2012.

Wang, F. X., Wang, L., Koike, T., Zhou, H. C., Yang, K., Wang, A. H., and Li, W. L.: Evaluation and application of a fine-resolution 
global data set in a semiarid mesoscale river basin with a distributed biosphere hydrological model, J. Geophys. Res.-Atmos., 116, D21108, https://doi.org/10.1029/2011jd015990, 2011.

Wang, W., Wang. X. J., and Wang, P.: Assessing the applicability of GLDAS monthly precipitation data in China, Advances in Water Science, 25, 769-778, 2014 (in Chinese).

Wang, W., Cui, W., Wang, J., and Chen, X.: Evaluation of GLDAS1 and GLDAS-2 forcing data and Noah model simulations over China at monthly scale, J. Hydrometeorol., 17, 2815-2833, https://doi.org/10.1175/JHM-D-15-0191.1, 2016a.

Wang, W., Lu, H., Yang, D.-W., Khem, S., Jiao, Y., Gao, B., Peng, X.-T., and Pang, Z.-G.: Modelling Hydrologic Processes in the Mekong River Basin Using a Distributed Model Driven by Satellite Precipitation and Rain Gauge Observations, Plos One, 11, e0152229, https://doi.org/10.1371/journal.pone.0152229, 2016b.

Wang, Y., Nan, Z., Chen, H., and Wu, X.: Correction of daily precipitation data of ITPCAS dataset over the Qinghai-Tibetan Plateau with KNN model, Geoscience and Remote Sensing Symposium, 593-596, https://doi.org/10.1109/IGARSS.2016.7729148, 2016.

Wu, J. and Gao, X.-J.: A gridded daily observation dataset over China region and comparison with the other datasets, Chin. J. Geophys., 56, 1102-1111, https://doi.org/10.6038/cjg20130406, 2013.

Xie, X., He, J.-H., and Qi, L.: A review on applicability evaluation of four reanalysis datasets in China, Journal of Meteorology \& Environment, 27, 58-65, 2011.

$\mathrm{Xu}, \mathrm{R}$., Tian, F., Yang, L., Hu, H., Lu, H., and Hou, A.: Ground Validation of GPM IMERG and TRMM 3B42V7 Rainfall Products over Southern Tibetan Plateau Based on a High-Density Rain-Gauge Network, J. Geophys. Res.-Atmos., 122, 910-924, https://doi.org/10.1002/2016JD025418, 2017.
Xue, B.-L., Wang, L., Yang, K., Tian, L.-D., Qin, J., Chen, Y.-Y., Zhao, L., Ma, Y.-M., Toshio, K., Hu, Z.-Y., and Li, X.-P.: Modeling the land surface water and energy cycles of a mesoscale watershed in the central Tibetan Plateau during summer with a distributed hydrological model, J. Geophys. Res.-Atmos., 118, 8857-8868, https://doi.org/10.1002/jgrd.50696, 2013.

Yang, K., Huang, G. W., and Tamai, N.: A hybrid model for estimating global solar radiation, Sol. Energ., 70, 13-22, https://doi.org/10.1016/S0038-092x(00)00121-3, 2001.

Yang, K., Koike, T., and Ye, B. S.: Improving estimation of hourly, daily, and monthly solar radiation by importing global data sets, Agr. Forest Meteorol., 137, 43-55, https://doi.org/10.1016/j.agrformet.2006.02.001, 2006.

Zhang, L., Liu, H., Ye, Y., and Huang, C.: Distributed modeling of shortwave solar radiation distribution over the Tibetan Plateau, J. Natural Resources, 25, 811-821, https://doi.org/10.11849/zrzyxb.2010.05.012, 2010.

Zhao, T. B., Fu, C. B., Ke, Z. J., and Guo, W.: Global Atmosphere Reanalysis Datasets: Current Status and Recent Advances, Adv. Earth Sci., 25, 242-254, 2010.

Zhao, F. and Zhu, J.: Assessing Quality of Grid Daily Precipitation Datasets in China in Recent 50 Years, Plateau Meteorology, 34, 50-58, https://doi.org/10.7522/j.issn.1000-0534.2013.00141, 2015. 